\title{
Influence OF Mold CAVITY SuRfaCe ON FLuidity OF Plastics
}

\author{
StANEK, M.; MANAS, M.; DRGA, T. \& MANAS, D.
}

Abstract: The fluidity of polymers is affected by many parameters inc. mold design. Evaluation of set of data obtained by experiments in which the testing conditions were widely changed shows that the quality of cavity surface and technological parameters (injection rate, injection pressure and gate size) has substantial influence on the length of flow.

Key words: injection molding, mold, polymer, surface roughness, fluidity
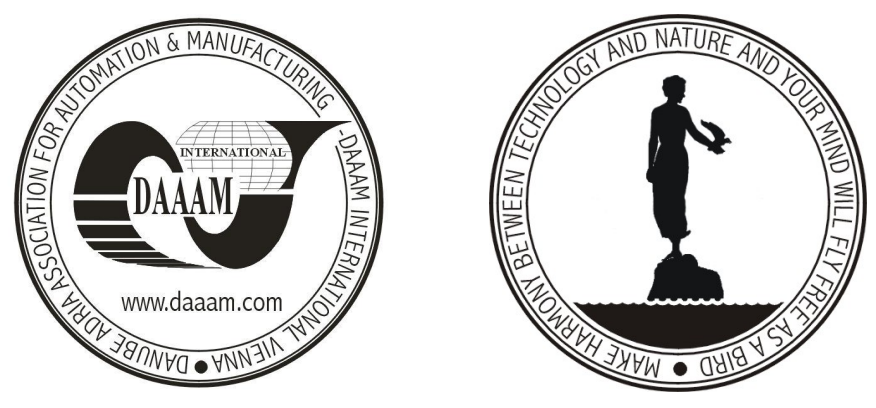

Authors' data: Ing. Ph.D. Stanek, M[ichal]; Ing. Ph.D. Assoc. Prof. Manas, M[iroslav]; Ing. Drga, T[omas]; Ing. Ph.D. Manas, D[avid], Tomas Bata University in Zlin, Faculty of Technology, Department of Production Engineering, TGM 275, 76272 Zlín, Czech Republic, stanek@ft.utb.cz, manas@ft.utb.cz, drga@ft.utb.cz, dmanas@ft.utb.cz

This Publication has to be referred as: Stanek, M.; Manas, M.; Drga, T. \& Manas, D. (2007). Influence of Mold Cavity Surface on Fluidity of Plastics, Chapter 55 in DAAAM International Scientific Book 2007, B. Katalinic (Ed.), Published by DAAAM International, ISBN 3-901509-60-7, ISSN 1726-9687, Vienna, Austria DOI: $10.2507 /$ daaam.scibook.2007.55 